\title{
Chin-Shan Community Cardiovascular Cohort in Taiwan-baseline data and five-year follow-up morbidity and mortality
}

\author{
Yuan-Teh Lee, ${ }^{\mathrm{a}, *}$, Ruey S. Lin ${ }^{\mathrm{b}}$, Fung C. Sung ${ }^{\mathrm{b}}$, Chi-Yu Yang ${ }^{\mathrm{a}}$, Kuo-Liong Chien ${ }^{\mathrm{a}}$, \\ Wen-Jone Chen ${ }^{\mathrm{a}}$, Ta-Chen $\mathrm{Su}^{\mathrm{a}}$, Hsiu-Ching Hsu ${ }^{\mathrm{a}}$, Yuh-Chen Huang ${ }^{\mathrm{a}}$ \\ ${ }^{a}$ Department of Internal Medicine, National Taiwan University College of Medicine, 7 Chung-Shan South Road, Taipei, Taiwan 100 \\ ${ }^{\mathrm{b} N a t i o n a l ~ T a i w a n}$ University College of Public Health, Taipei, Taiwan \\ Received 27 October 1997; received in revised form 23 November 1999, accepted 10 January 2000
}

\begin{abstract}
A cohort consisting of 3602 residents ( $82.8 \%$ of the target population) aged 35 years and older was established in 1990 in the ChinShan Community, a suburb 20 miles outside of metropolitan Taipei, Taiwan. The long-term objective was to investigate the prospective impact on cardiovascular health in a society undergoing transition from a developing to a developed nation. This article presents the study design, selected baseline risk factors of cardiovascular diseases (CVD), and CVD events at the 5-year follow-up evaluation with an emphasis on sociodemographic differences. The multivariate logistic regression analyses revealed that white-collar individuals were more likely than blue-collar workers to have dyslipidemia including high-density lipoprotein cholesterol (HDL-C) levels $<35 \mathrm{mg} / \mathrm{dl}$ [odds ratio $(\mathrm{OR})=1.7,95 \%$ confidence interval $(\mathrm{CI})=1.2-2.4]$ and low-density lipoprotein cholesterol $(\mathrm{LDL}-\mathrm{C})$ levels $\geqslant 160 \mathrm{mg} / \mathrm{dl}(\mathrm{OR}=1.3,95 \%$ $\mathrm{CI}=1.0-1.7)$. However, they were at slightly lower risk for stroke and CVD/sudden death, and at moderately higher risk for coronary artery disease and diabetes, although both these trends were not significant. Men were more likely than women to have HDL-C levels $<35$ $\mathrm{mg} / \mathrm{dl}(\mathrm{OR}=1.8,95 \% \mathrm{CI}=1.4-2.2)$, but they were less likely to have LDL-C levels $\geqslant 160 \mathrm{mg} / \mathrm{dl}(\mathrm{OR}=0.7,95 \% \mathrm{CI}=0.6-0.8)$. The risk of CVD/sudden death was higher for men than for women during the follow-up period $(\mathrm{OR}=1.9,95 \% \mathrm{CI}=1.3-2.9)$. This could be due to risk factors such as a much higher prevalence of tobacco $(61.9 \%$ vs. $4.5 \%)$ and alcohol $(43.7 \%$ vs. $6.4 \%)$ use in men. In conclusion, individuals of higher socioeconomic status have a higher prevalence of dyslipidemia but slightly lower 5-year incidence of CVD events. (C) 2000 Elsevier Science, Inc. All rights reserved.
\end{abstract}

Keywords: Cardiovascular disease; Dyslipidemia; Longitudinal study; Sociodemographic difference; Taiwan; Transitioning society

\section{Introduction}

Since the Framingham Study [1,2], considerable research efforts have been expended to conduct prospective studies investigating factors associated with the development of cardiovascular diseases (CVD). Such efforts have provided important information, increased the awareness of cardiovascular risk factors, and helped to develop strategies for lipid, hypertension, and diabetes control, exercise, and smoking prevention [3-15]. It has been documented that mortality from strokes and ischemic or coronary heart disease has declined in developed Western countries since the mid1960s [16]. However, few well-designed prospective studies have examined risk factors for cardiovascular diseases in populations of developing and underdeveloped areas.

* Corresponding author. Tel.: 886-2-2356-2000; fax: 886-2-2321-7522.

E-mail address: ytlee@ ha.mc.ntu.edu.tw
Beaglehole [17] named cardiovascular disease "a haunting epidemic" in developing countries ever since the World Health Organization encouraged CVD prevention in 1991 [18]. By the year 2000, cardiovascular disease will be the leading cause of death in many developing countries [19]. For example, mortality from ischemic heart disease doubled in Singapore from 1959 through 1983. Hughes [20] considered this increase to be the consequence of increasing wealth. Rapid economic development over the past few decades has caused Singapore to become the highest ranking nation in Asia in terms of per capita income, second only to Japan. Taiwan, like many Asian countries, has seen a decline in deaths related to infectious diseases but has experienced a rapid increase in deaths resulting from chronic diseases, especially from cancer and cardiovascular diseases. Relative to the populations of Western countries, the Taiwanese population has a higher mortality rate from strokes and a lower death rate from coronary heart disease. Among CVD deaths in Taiwan (142 per 100,000 in 1990), $49.1 \%$ were from stroke, $39.4 \%$ from 
heart disease, and $11.4 \%$ from hypertensive disease [21]. The risk of a stroke-associated death is four times higher in the Taiwanese population than in the American population [22].

Taiwan currently has the second highest population density in the world and the third highest per capita income in Asia. According to recent projections, this island nation will soon be able to classify itself as a developed country [23]. It is interesting to study the trends in cardiovascular diseases associated with this socioeconomic change, as well as to investigate the multiple interrelated characteristics of lifestyle, selected biochemistries of blood and urine, imaging studies, and other physiological conditions in this transitional society.

In 1990, a longitudinal study cohort was established in Chin-Shan, a suburban community 20 miles outside of Taipei, Taiwan. The primary objective of the Chin-Shan Community Cardiovascular Cohort (CCCC) Project was to measure the trends in and determinants of cardiovascular morbidity and mortality in a community that is experiencing rapid socioeconomic transition. The recent development of reliable blood chemistry analyses and ultrasonic imaging of heart and soft tissues has permitted the study team to initiate a thorough prospective investigation, identifying biochemical and physiological factors for cardiovascular diseases in this population. This report describes the study design, different findings by sociodemographic factors at baseline, and CVD events that occurred in the 5-year follow-up evaluation.

\section{Methods}

\subsection{Study design and recruitment}

Recruitment of study participants was initiated through extensive contacts with local population authorities to identify households with individuals of eligible age, excluding those in institutions. About $36 \%$ of the population in the Chin-Shan area were aged 35 and above in 1990; this percentage was reflective of the entire population in Taiwan. We contacted 4349 individuals of whom 747 (17.2\%) did not respond, including 95 refusals and 652 individuals who could not be reached due to working outside of the local community. Of the 3602 (response rate $82.8 \%$ ) individuals who participated in the baseline survey, $47.3 \%$ were men and $52.7 \%$ were women. Female participants were, on average, younger and usually not employed outside the home (Table 1). The level of education reported by participants also demonstrated a typical characteristic of developing Asian countries: individuals, especially women, who had not received formal education, were usually senior citizens. Most participants belonged to families headed by blue-collar employees. A new cohort is being recruited every 5 years and included into the project in order to distinguish the possible cohort effect existing in the population.

\subsection{Home visiting and baseline examination}

A clinic was set up at the Chin-Shan Community Health Center (CCHC) by the study team, which consisted of 20
Table 1

Percentage distribution of demographic characteristics of participants by gender in the Chin-Shan Community Cardiovascular study at baseline

\begin{tabular}{lcc}
\hline Characteristics & Male $(n=1703)$ & Female $(n=1899)$ \\
\hline Ages & & \\
$35-44$ & 23.7 & 28.0 \\
$45-54$ & 23.1 & 26.7 \\
$55-64$ & 28.9 & 24.0 \\
$65-74$ & 18.0 & 15.4 \\
$75+$ & 6.3 & 5.9 \\
Married & & \\
Yes & 89.4 & 82.7 \\
No & 10.6 & 17.3 \\
Occupation & & \\
White collar & 15.2 & 11.8 \\
Blue collar & 52.4 & 18.0 \\
Other & 2.3 & 2.4 \\
None & 30.1 & 67.5 \\
Insurance & & \\
Government & 6.1 & 5.0 \\
Labor/farmer/fisherman & 83.2 & 79.9 \\
Others & 10.7 & 15.1 \\
Education & & \\
None & 28.1 & 51.7 \\
1-9 years & 63.2 & 45.1 \\
10-12 years & 5.6 & 2.6 \\
13+ years & 3.1 & 0.6 \\
\hline
\end{tabular}

Gender differences of all variables were all significant at the 0.05 level.

senior medical students, 2 assistant nurses, 10 cardiologists and local practitioners, and the officers of CCHC. Fourteen community leaders who were familiar with the families in the community also assisted with the identification and recruitment of potential participants. A letter describing the purpose and procedure of the study was delivered to each potential participant as an invitation to the clinic. For nonrespondents, trained medical students were sent door-to-door, with the assistance of community leaders, to conduct a 2-h interview with each participant. These interviews collected baseline information such as demographic characteristics, lifestyle factors, dietary characteristics, and personal and family histories of diseases and hospitalization. With the consent of the participants, a physician and senior medical students conducted physical examinations and laboratory tests including electrocardiography, echocardiography, fundoscopic examination, and sonographic measurement of abdominal subcutaneous fat. Achilles tendon thickness was also measured using ultrasonic images.

Various data collected from the interviews, physical examinations, laboratory tests, and biochemical examinations are shown in Appendix 1. Urine and blood specimens were collected to determine levels of creatinine, uric acid, serum total cholesterol, serum triglycerides, low-density lipoprotein cholesterol (LDL-C), high-density lipoprotein cholesterol (HDL-C), lipoprotein(a), and apoliproproteins. Fasting blood samples for diabetes screening were also obtained from participants. Additionally, a 75-g oral dextrose test was given and glucose and insulin levels were determined 2 $h$ after the glucose load [24]. Participants were later in- 
formed of their blood pressure and plasma lipid results. Calibration was conducted for every 20 specimens in the laboratory for blood and urine analyses. The methods of specimen and analyses are listed in Appendix 2. The results of the physical exams, laboratory tests, and imaging studies were reviewed independently by senior cardiologists.

Participants whose physical exams or laboratory test results revealed abnormal findings were requested to have a second examination at the Chin-Shan Community Health Center or the National Taiwan University Hospital (NTUH). Those with elevated blood pressure, cholesterol, or other findings were advised to seek medical follow-up, which was provided by the CCHC, local practitioners, and NTUH on an as-needed basis. Interventions were also available to participants on a voluntary basis for hypertension control and lipid management [25].

\subsection{Follow-up, study team, and diagnoses}

The study team invited all participants to have biennial follow-up visits and examinations in 1992-93 and 1994-95 at the CCHC. The core personnel met every other week to discuss the field tasks being conducted, and medical students again participated in the study team as interviewers. Prior to joining the field tasks, all students were required to undergo a 2-week training course in internal medicine related to this study at the Department of Internal Medicine,

Table 2

Percentage distribution of lifestyle and baseline health status by gender in the Chin-Shan Community Cardiovascular study at baseline

\begin{tabular}{llll}
\hline & $\begin{array}{l}\text { Male } \\
(n=1703)\end{array}$ & $\begin{array}{l}\text { Female } \\
(n=1899)\end{array}$ & $\begin{array}{l}\text { Difference } \\
(95 \% \mathrm{CI})\end{array}$ \\
\hline Smoking: current & 61.9 & 4.5 & $57.4(54.9,59.9)$ \\
Alcohol: current & 43.7 & 6.4 & $37.3(34.7,39.9)$ \\
Betel nut: current & 3.6 & 0.05 & $3.5(2.2,4.8)$ \\
Tea: current & 31.4 & 18.5 & $12.9(10.1,15.7)$ \\
Coffee: current & 6.9 & 8.8 & $-1.9(-0.1,-3.7)$ \\
Exercise or laborious job: & & & \\
$\quad$ yes & 69.4 & 49.3 & $20.1(17.0,23.2)$ \\
Body mass index, kg/m ${ }^{2}$ & & & \\
$\quad$ Mean \pm SD & $23.0 \pm 3.3$ & $24.6 \pm 5.7$ & $-1.6(-1.8,-1.4)$ \\
$\quad$ 75th percentile & 25.0 & 26.0 & \\
$\quad$ 90th percentile & 27.2 & 28.3 & \\
Diabetes mellitus: yes & 8.5 & 8.6 & $-0.1(-1.9,1.7)$ \\
CVA: yes & 2.5 & 1.9 & $0.6(-0.2,1.4)$ \\
CAD: yes & 4.5 & 3.5 & $1.0(-0.3,2.3)$ \\
Blood pressure (mmHg) & & & \\
$\quad$ Hypertension (Yes) & & & $-5.1(-8.0,-2.2)$ \\
$\quad$ Crude & 25.7 & 30.8 & $-7.0(-10.0,-4.0)$ \\
$\quad$ Age-adjusted & 25.0 & 32.0 & \\
$\quad$ Systolic $\geqslant 140$ & & & $-6.0(-8.7,-3.3)$ \\
$\quad$ Crude & 19.7 & 25.7 & $-8.0(-10.7,-5.2)$ \\
$\quad$ Age-adjusted & 18.9 & 26.9 & $-1.4(-0.9,3.7)$ \\
$\quad$ Diastolic, $\geqslant 90$ & & & $-1.8(-0.5,5.1)$ \\
$\quad$ Crude & 14.1 & 15.5 & \\
$\quad$ Age-adjusted & 14.0 & 15.8 &
\end{tabular}

All numbers are in percent except body mass index. CI: confidence interval; SD: standard deviation; CVA: cerebrovascular accident; CAD: coronary artery disease.

${ }^{a}$ Male-to-female difference.
NTUH. Techniques in measuring blood pressure, taking notes, interviewing, teaching, interpersonal skills, as well as some public health issues, were emphasized in the training course. During the survey period, staff and students usually held discussion sessions after home visits. The medical students were responsible for administering the questionnaire and interviewing participants. Information on general health, events of cardiovascular illness (hypertension, stroke, and coronary heart disease), and hospitalizations and anthropometric measurements were collected at this time.

Urine and blood specimens were requested again during the follow-up visits. In the first follow-up examination, measurements of apolipoprotein A1, apolipoprotein B, lipoprotein(a), and coagulation factors (including fibrinogen, plasminogen activator inhibitor, tissue plasminogen activator, factor VII antigen, factor VII, and factor VIII) were taken. All samples collected were stored at $-76^{\circ} \mathrm{C}$ using liquid nitrogen if not shipped at $4^{\circ} \mathrm{C}$ to NTUH clinic laboratory within $8 \mathrm{~h}$ for analyses.

\subsection{Monitoring morbidity and mortality}

Events of selected CVDs (identified in the follow-up visits) and deaths (identified from the government vital registry) were reviewed by physicians on the Committee of Mortality and Morbidity within the study team. Medical records were used to determine the likely cause of death. Four cardiologists were responsible for reviewing the questionnaires, medical records, and laboratory reports to determine

Table 3

Means, standard deviations (in parentheses) for selected levels of lipid and other factors by gender in the Chin-Shan Community Cardiovascular study at baseline

\begin{tabular}{lccc}
\hline $\begin{array}{l}\text { Male } \\
(n=1703)\end{array}$ & $\begin{array}{l}\text { Female } \\
(n=1899)\end{array}$ & $\begin{array}{l}\text { Difference } \\
(95 \% \mathrm{CI})\end{array}$ \\
\hline $\begin{array}{c}\text { Total cholesterol } \\
\quad(\mathrm{mg} / \mathrm{dl})\end{array}$ & $192.5(44.7)$ & $202.8(45.8)$ & $-10.3(-13.3,-7.3)$ \\
Triglycerides (mg/dl) & $128.5(99.2)$ & $123.4(92.0)$ & $6.3(-0.2,11.8)$ \\
Lipoprotein cholesterol & & & \\
$\quad(\mathrm{mg} / \mathrm{dl})$ & & & \\
HDL-C & $46.3(12.9)$ & $48.5(12.4)$ & $-2.2(-3.8,-1.4)$ \\
LDL-C & $132.7(43.3)$ & $142.2(44.5)$ & $-9.5(-15.2,-3.8)$ \\
Lipoprotein(a) & $14.0(15.3)$ & $14.5(15.5)$ & $-0.5(-1.5,0.5)$ \\
HDL/LDL ratio & $0.40(0.2)$ & $0.38(0.2)$ & $0.02(0.01,0.03)$ \\
Uric acid (mg/dl) & $6.4(1.6)$ & $5.0(1.5)$ & $1.4(1.3,1.5)$ \\
Blood pressure & & & \\
$\quad(\mathrm{mmHg})$ & & & \\
Systolic & $124.2(19.4)$ & $126.9(21.8)$ & $-2.7(-4.1,-1.3)$ \\
Diastolic & $77.0(11.2)$ & $77.3(11.2)$ & $-0.3(-1.1,0.4)$ \\
Belly-skin-fold (mm) & $12.0(7.4)$ & $17.6(8.9)$ & $-5.6(-6.2,-5.0)$ \\
Left upper arm girth & & & \\
$\quad(\mathrm{cm})$ & $25.7(5.1)$ & $26.0(4.1)$ & $-0.3(-0.5,-0.1)$ \\
Total protein (mg/dl) & $7.72(0.7)$ & $7.84(0.7)$ & $-0.12(-0.2,-0.1)$ \\
Albumin (mg/dl) & $4.67(0.5)$ & $4.67(0.6)$ & $0.0(-0.04,0.04)$ \\
Pre-albumin (mg/dl) & $29.3(9.8)$ & $25.0(6.4)$ & $3.7(3.2,4.2)$ \\
Trans-ferritin (mg/dl) & $270.5(51.4)$ & $283.1(52.7)$ & $-12.6(-16.1,-9.1)$ \\
\hline
\end{tabular}

CI: confidence interval; HDL-C: high-density lipoprotein cholesterol; LDL-C: low-density lipoprotein cholesterol.

${ }^{a}$ Male-to-female difference. 
whether each event met the protocol established by the project steering committee. Relatives of nonrespondents were contacted to obtain information on the health status of uncooperative individuals. Medical records were reviewed at CCHC, local clinics, and National Taiwan University Hospital. Using national vital statistics records, the study team was able to obtain information about deceased participants and determine the attributed cause of death.

Diagnostic criteria for cardiovascular diseases and deaths were adapted from the recommendations of the New York Heart Association and the American Heart Association [2628]. Hypertension was diagnosed in individuals with systolic blood pressure at or above $140 \mathrm{mmHg}$ and/or diastolic blood pressure at or above $90 \mathrm{mmHg}$, and in persons who were on antihypertension medications. Diabetes mellitus was diagnosed in those with fasting blood sugar levels higher than $140 \mathrm{mg} / \mathrm{dl}$ and in those with oral hypoglycemic agents or insulin treatment. Cerebrovascular disease was defined as a history of hemiparesis or hemiplegia confirmed by neurologists from NTUH by physical examination. Coronary heart disease was diagnosed by a history of myocardial infarction or electrocardiographic evidence of definite $\mathrm{Q}$ wave was found by the Minnesota Code [29].

\subsection{Evaluation}

For the baseline information reported in this article, we briefly described the study populations by gender, sociodemographic characteristics, lifestyle, baseline health status, and lipid profiles using either mean differences or differences in proportion to abnormal values. The $95 \%$ confidence intervals (CI) were provided for comparisons. An individual with a total cholesterol level $\geqslant 240 \mathrm{mg} / \mathrm{dl}$, triglyceride level $\geqslant 200 \mathrm{mg} / \mathrm{dl}$, HDL-C $<35 \mathrm{mg} / \mathrm{dl}$, LDL-C $\geqslant 160 \mathrm{mg} / \mathrm{dl}$, or lipoprotein(a) $\geqslant 32.5 \mathrm{mg} / \mathrm{dl}$ was considered to have dyslipidemia, in accordance with the Adult Treatment Panel II in the National Cholesterol Education Program (NCEP) of the U.S. [30]. Multivariable logistic regression analyses were also used to measure the relative risk of hypertension (yes vs. no), high LDL-C ( $\geqslant 160$ vs. $<160 \mathrm{mg}$ / dl), low HDL-C ( $<35$ vs. $\geqslant 35 \mathrm{mg} / \mathrm{dl})$, and high TG $(\geqslant 200$ vs. $<200 \mathrm{mg} / \mathrm{dl})$. Odds ratios (OR) and $95 \%$ CIs were estimated for different sociodemographic factors: gender, age, martial status, occupation, insurance status, and education level. In addition to reporting the incidence of selected CVDs and mortality from selected deaths in the follow-up period, logistic regression analyses were also used to measure the risk of CAD, stroke, DM, and mortality from CVD/ sudden deaths for the above-mentioned sociodemographic factors.

\section{Results}

\subsection{Baseline lifestyle and health status of study participants}

Cigarette, alcohol, and tea use was prevalent in male study participants (Table 2): $61.9 \%$ of males were current smokers and $43.7 \%$ were regular users of alcohol. About $5 \%$ of female participants were smokers and $6 \%$ were alcohol users. Women had a higher prevalence of hypertension (32.0\% vs. $25.0 \%$; $95 \% \mathrm{CI}$ of the difference $=4.0-10.0 \%$ ) and a higher average body mass index $\left(24.6 \mathrm{vs} .23 .0 \mathrm{~kg} / \mathrm{m}^{2}\right.$, $95 \% \mathrm{CI}$ of the difference $=1.4-1.8 \mathrm{~kg} / \mathrm{m}^{2}$ ) than men. The prevalence of diabetes mellitus was similar between men and women; $8.5 \%$ for men and $8.6 \%$ for women. About $2.5 \%$ of the men had had a cerebrovascular accident (CVA) and $4.5 \%$ of the men had coronary artery disease (CAD). While both events were more prevalent in men than in women $(1.9 \%$ and $3.5 \%$, respectively), these differences were not statistically significant.

\subsection{Blood biochemistries}

Table 3 shows the average levels of lipid profiles and blood pressure. The average total cholesterol was significantly higher in women than in men (202.8 vs. $192.5 \mathrm{mg} / \mathrm{dl}$; $95 \% \mathrm{CI}$ of the difference $=7.3-13.3 \mathrm{mg} / \mathrm{dl})$. Average levels of both HDL-C (48.5 vs. $46.3 \mathrm{mg} / \mathrm{dl}$; $95 \% \mathrm{CI}$ of the difference $=1.4-3.8 \mathrm{mg} / \mathrm{dl})$ and LDL-C (142.2 vs. $132.7 \mathrm{mg} / \mathrm{dl}$; $95 \% \mathrm{CI}$ of the difference $=3.8-15.2 \mathrm{mg} / \mathrm{dl})$ were significantly higher in women than in men. There was no significant difference between men and women in average level of lipoprotein(a). However, the average triglyceride level was higher in men than in women (128.5 vs. $123.4 \mathrm{mg} / \mathrm{dl})$ at a borderline significance level. Average systolic blood pressure was also higher in women than in men (126.9 vs. 124.2 $\mathrm{mmHg} ; 95 \% \mathrm{CI}$ of the difference $=1.3-4.1 \mathrm{mmHg}$ ). Other average measurements that were significantly greater in women than in men included average belly-skin fold (17.6 vs. $12.0 \mathrm{~mm})$, left upper arm girth (26.0 vs. $25.7 \mathrm{~mm})$, total protein (7.84 vs. $7.72 \mathrm{mg} / \mathrm{dl})$, and trans-ferritin (283.1 vs. $270.5 \mathrm{mg} / \mathrm{dl})$. Men had higher levels of pre-albumin than women ( 29.3 vs. $25.0 \mathrm{mg} / \mathrm{dl})$.

Table 4 compares the percentage of individuals with abnormal lipid profiles and other selected blood measurements between males and females. Calculation of crude and age-adjusted differences in the percentage of participants with dyslipidemia also revealed that the abnormalities were generally significantly more prevalent in women than in men in all categories. However, the largest gender difference in lipoprotein cholesterol was observed in prevalence of low levels of HDL-C with an age-adjusted difference of $8.9 \%$, higher in men than in women.

Logistic regression analyses were constructed to estimate the predictability of gender, age, marital status, occupation, education level, and health insurance status in hypertension and dyslipidemia at baseline (Table 5). White-collar individuals, compared with blue-collar individuals, were at elevated risk of having higher LDL-C and TG, and lower HDL-C, but not hypertension. Retired or unemployed individuals showed a similar risk profile. This table also shows that compared with women, men were less likely to have a higher LDL-C level (OR $=0.7,95 \% \mathrm{CI}=0.6-0.8)$, but 
Table 4

Crude and age-adjusted percent of study participants with dyslipidemia and elevated levels in other components by gender in the Chin-Shan

Community Cardiovascular study at baseline

\begin{tabular}{|c|c|c|c|}
\hline Factor & $\begin{array}{l}\text { Male } \\
(n=1703)\end{array}$ & $\begin{array}{l}\text { Female } \\
(n=1899)\end{array}$ & $\begin{array}{l}\text { Difference }^{a} \\
(95 \% \mathrm{CI})\end{array}$ \\
\hline \multicolumn{4}{|c|}{$\begin{array}{l}\text { Total cholesterol } \\
\qquad(\geqslant 240 \mathrm{mg} / \mathrm{dl})\end{array}$} \\
\hline Crude & 13.9 & 19.6 & $-5.7(-8.1,-3.3)$ \\
\hline Adjusted & 13.8 & 20.3 & $-6.5(-9.0,-4.0)$ \\
\hline \multicolumn{4}{|l|}{$\begin{array}{l}\text { Triglycerides } \\
\qquad(\geqslant 200 \mathrm{~m}\end{array}$} \\
\hline Crude & 25.2 & 23.1 & $2.1(0.7,3.5)$ \\
\hline Adjusted & 25.6 & 23.6 & $2.0(0.6,4.4)$ \\
\hline \multicolumn{4}{|c|}{$\begin{array}{l}\text { Lipoprotein cholesterol } \\
\qquad(\mathrm{mg} / \mathrm{dl})\end{array}$} \\
\hline \multicolumn{4}{|c|}{ HDL-C, $<35$} \\
\hline Crude & 21.8 & 13.6 & $8.2(5.7,10.7)$ \\
\hline Adjusted & 22.9 & 14.0 & $8.9(6.4,11.4)$ \\
\hline \multicolumn{4}{|c|}{ LDL-C, $\geqslant 160$} \\
\hline Crude & 23.3 & 28.4 & $-5.1(-8.9,-2.3)$ \\
\hline Adjusted & 23.1 & 31.3 & $-8.2(-11.1,-5.3)$ \\
\hline \multicolumn{4}{|c|}{ Lipoprotein(a), $\geqslant 32.5$} \\
\hline Crude & 9.5 & 12.2 & $-2.7(-4.7,-0.7)$ \\
\hline Adjusted & 9.5 & 12.3 & $-2.8(-4.8,-0.8)$ \\
\hline \multicolumn{4}{|c|}{ HDL/LDL Ratio, $<0.20$} \\
\hline Crude & 10.0 & 8.6 & $1.4(-0.5,3.3)$ \\
\hline Adjusted & 9.9 & 8.4 & $1.5(-0.4,3.4)$ \\
\hline \multicolumn{4}{|c|}{ Uric acid $(\geqslant 7.9 \mathrm{mg} / \mathrm{dl})$} \\
\hline Crude & 16.9 & 4.3 & $12.6(10.6,14.6)$ \\
\hline Adjusted & 16.9 & 4.4 & $12.5(10.5,14.5)$ \\
\hline \multicolumn{4}{|c|}{ Total protein $(\geqslant 8.5 \mathrm{mg} / \mathrm{dl})$} \\
\hline Crude & 8.5 & 12.2 & $-3.7(-5.7,-1.7)$ \\
\hline Adjusted & 8.5 & 12.2 & $-3.7(-5.7,-1.7)$ \\
\hline \multicolumn{4}{|c|}{ Albumin $(\geqslant 5.3 \mathrm{mg} / \mathrm{dl})$} \\
\hline Crude & 10.5 & 9.7 & $-0.8(-2.8,1.2)$ \\
\hline Adjusted & 10.7 & 9.8 & $-0.9(-2.9,1.1)$ \\
\hline \multicolumn{4}{|c|}{ Pre-albumin $(\geqslant 36 \mathrm{mg} / \mathrm{dl})$} \\
\hline Crude & 16.3 & 5.0 & $11.3(9.3,13.3)$ \\
\hline Adjusted & 16.6 & 5.1 & $11.5(9.5,13.5)$ \\
\hline \multicolumn{4}{|c|}{ Trans-ferritin $(\geqslant 341 \mathrm{mg} / \mathrm{dl})$} \\
\hline Crude & 7.6 & 11.9 & $-4.3(-5.3,-3.3)$ \\
\hline Adjusted & 7.7 & 11.5 & $-3.8(-4.8,-2.8)$ \\
\hline
\end{tabular}

CI: confidence interval; HDL-C: high-density lipoprotein cholesterol; LDL-C: low-density lipoprotein cholesterol.

${ }^{\text {a } M a l e-t o-f e m a l e ~ d i f f e r e n c e . ~}$

more likely to have a lower HDL-C level (OR $=1.8,95 \%$ $\mathrm{CI}=1.4-2.2)$, and a higher TG level $(\mathrm{OR}=1.2,95 \% \mathrm{CI}=$ $1.0-1.4)$.

\subsection{Cardiovascular events found in the follow-up surveys}

The study team completed the first follow-up survey in September 1993 and the second follow-up survey in October 1995 with a response rate of $88.7 \%$ among the 3368 survivors in the 1995 survey ( $n=2,988,45.3 \%$ males and $54.7 \%$ females). Most of the nonrespondents $(n=380$ or $11.3 \%$ ) had either moved away or were unreachable. In these two follow-up surveys, 752 individuals with 969 new events of cardiovascular disease and 217 new cases of diabetes were diagnosed (Table 6). As of February 1996, the national vital statistics identified 369 deaths. Overall, men tended to have higher event rates than women in both mortality and incidence of diseases, except for strokes where men and women had similar incidence rates. Table 7 shows that men were more likely than women to have a higher rate from $\mathrm{CVD} /$ sudden death $(\mathrm{OR}=1.9,95 \% \mathrm{CI}=1.3-2.9)$. White-collar workers were less likely than blue-collar workers to have stroke or CVD/sudden deaths, but these differences were not statistically significant. White-collar workers also exhibited moderately elevated odds ratios for the incidence of CAD and DM, but this effect was not at a statistically significant level. Individuals with at least a primary school education had higher incidence of DM than did individuals with no formal education.

\section{Discussion}

The baseline recruitment ( $82.8 \%$ response rate) and the follow-up (response rate $88.7 \%$ ) were successful for at least two reasons: (a) the study team was able to organize an enthusiastic group to make door-to-door visits to eligible individuals' participation, and (b) community leaders' assistance in the project made participant recruitment much easier. In addition, community residents with higher awareness of individual health were pleased to receive a comprehensive examination to look for precursors of cardiovascular events. The nonrespondents were mainly young individuals who worked outside the Chin-Shan area.

There are many population-based prospective studies in North America (e.g., Framingham, Bogalusa, Evans County, Stanford, Minnesota, ARIC, Honolulu, and Manitoba) and Europe [e.g., World Health Organization Monitoring and Cardiovascular (MONICA) Projects] [1-15,31-33]. While they have certainly provided important epidemiologic clues for understanding the pathophysiology of CVD, few studies have prospectively examined CVD in Asian populations. Although the MONICA Projects include Sino-MONICA and Japan-MONICA [33], the basic objective of MONICA is to measure a 10-year trend in cardiovascular mortality and morbidity and the associated population-based risk factors. The Taiwan CCCC study is unique because its objective is to observe the impacts of socioeconomic change on the development of CVD in a society in transition. In addition, this study was designed to add a new cohort to the study pool every 5 years. Newly eligible 35- to 39 -year-old residents in Chin-Shan are being recruited into the study at 5-year intervals, allowing for future investigation of the cohort effect.

In addition, the CCCC study is distinct from other studies because it primarily consists of blue-collar workers and includes a large number of housewives and other female participants. This population is representative of the general Taiwanese population, but has a lower overall education level than the urban population. This difference in education level may be linked to higher rates of risky behaviors such as smoking in men and higher fat consumption. Even if this is the case, it is still a valid goal to study dyslipidemia and 
Table 5

Odds ratios of hypertension and dyslipidemia by sociodemographic factors in the Chin-Shan Community Cardiovascular study at baseline

\begin{tabular}{|c|c|c|c|c|}
\hline & $\begin{array}{l}\text { Hypertension } \\
\text { OR }(95 \% \text { CI })\end{array}$ & $\begin{array}{l}\text { LDL-C } \\
\text { OR }(95 \% \text { CI })\end{array}$ & $\begin{array}{l}\text { HDL-C } \\
\text { OR }(95 \% \mathrm{CI})\end{array}$ & $\begin{array}{l}\text { TG } \\
\text { OR }(95 \% \mathrm{CI})\end{array}$ \\
\hline \multicolumn{5}{|l|}{ Gender } \\
\hline Male & $0.96(0.8-1.2)$ & $0.7(0.6-0.8)$ & $1.8(1.4-2.2)$ & $1.2(1.0-1.4)$ \\
\hline Female & 1.0 & 1.0 & 1.0 & 1.0 \\
\hline \multicolumn{5}{|l|}{ Age } \\
\hline $35-54$ & 1.0 & 1.0 & 1.0 & 1.0 \\
\hline $55-64$ & $2.0(1.5-2.5)$ & $1.9(1.6-2.3)$ & $1.4(1.1-1.8)$ & $1.2(1.0-1.4)$ \\
\hline $65+$ & $2.5(1.9-3.3)$ & $1.8(1.5-2.3)$ & $1.4(1.0-1.8)$ & $1.1(0.9-1.4)$ \\
\hline \multicolumn{5}{|l|}{ Married } \\
\hline No & 1.0 & 1.0 & 1.0 & 1.0 \\
\hline Yes & $1.0(0.6-1.6)$ & $1.3(0.8-2.0)$ & $0.7(0.4-1.2)$ & $1.6(1.0-2.7)$ \\
\hline \multicolumn{5}{|l|}{ Occupation } \\
\hline Blue collar & 1.0 & 1.0 & 1.0 & 1.0 \\
\hline White collar & $1.1(0.8-1.5)$ & $1.3(1.0-1.7)$ & $1.7(1.2-2.4)$ & $1.4(1.1-1.9)$ \\
\hline Others $^{\mathrm{a}}$ & $1.1(0.9-1.5)$ & $1.2(1.0-1.5)$ & $1.4(1.1-1.9)$ & $1.4(1.1-1.7)$ \\
\hline \multicolumn{5}{|c|}{ School Education } \\
\hline None & 1.0 & 1.0 & 1.0 & 1.0 \\
\hline Yes & $1.1(0.9-1.4)$ & $1.1(0.9-1.3)$ & $1.1(0.9-1.4)$ & $1.2(1.0-1.5)$ \\
\hline \multicolumn{5}{|l|}{ Insurance } \\
\hline Government & 1.0 & 1.0 & 1.0 & 1.0 \\
\hline Labor $^{\mathrm{b}}$ & $1.1(0.7-1.8)$ & $0.9(0.7-1.3)$ & $0.9(0.6-1.4)$ & $0.9(0.7-1.3)$ \\
\hline Other & $1.2(0.7-2.0)$ & $0.9(0.7-1.4)$ & $1.2(0.8-1.9)$ & $1.0(0.7-1.5)$ \\
\hline
\end{tabular}

LDL-C: low-density lipoprotein cholesterol $\geqslant 160 \mathrm{mg} / \mathrm{dl}$; HDL-C: high-density lipoprotein cholesterol < $35 \mathrm{mg} / \mathrm{dl}$; TG: triglycerides $\geqslant 200 \mathrm{mg} / \mathrm{dl}$; OR: odds ratio; $\mathrm{CI}$ : confidence interval.

${ }^{\text {a }}$ Retired and unemployed.

${ }^{b}$ Labor insurance covered also farmers and fishermen.

other factors associated with the development of hypertension, ischemic heart disease, atherosclerosis, and other cardiovascular events. In planning this investigation, the study team observed that this target population is different from those of other studies. This population was in a higher risk group in terms of lipid profile according to the team's historical experience in this area. On the other hand, the population in this community devotes a large amount of time to farming, fishing, and other labor-intensive occupations.

In two studies done in the rural village of San-Chih, Taipei County, the prevalence of hyperlipidemia (total cholesterol level $\geqslant 250 \mathrm{mg} / \mathrm{dl}$ ) increased twofold from $5.5 \%$ in 1973 to $10.8 \%$ in 1991 [34,35]. A fivefold increase in CAD prevalence, from $0.6 \%$ to $3.1 \%$, was reported during the same time period. Chin-Shan is a more urban community than San-Chih; the Chin-Shan study cohort had a prevalence rate of $16.9 \%$ for hyperlipidemia (total cholesterol $\geqslant 240 \mathrm{mg} / \mathrm{dl}$ ) and a prevalence rate of $4.1 \%$ for CAD. As Taiwan makes its transition to a developed nation, the per capita daily energy consumption from fat has increased from $22 \%$ in 1971 to $28 \%$ in $1981,37 \%$ in 1991 , and $40 \%$ in 1995 [36]. As fat consumption continues to increase in Taiwan, we predict that the prevalence of dyslipidemia will also increase, particularly among uninformed populations.

Similar to blood lipid levels, smoking levels among participants of the CCCC study were consistent with those of the general population of Taiwan as reported by other cross-sectional studies [37-40]. The prevalence rate of smoking in
Chin-Shan was lower than the rates in areas of mainland China such as Beijing and Quangzhou (71\% and $78 \%$ for men and $3.2 \%$ and $31 \%$ for women, respectively). But the prevalence of abnormal total cholesterol was much lower for people in Beijing and Quangzhou (about $175 \mathrm{mg} / \mathrm{dl}$ on average) [41]. The average blood cholesterol level for this study cohort may be comparable with that of the U.S. population $[6,7,41]$. In addition, the prevalence of hypertension for men in the CCCC project was similar to that found in a study conducted in the U.S. [42]. CCCC women, though, were found to have a higher prevalence of hypertension than U.S. women [42]. Further-

Table 6

Incidence cases and rates (per 1000 person-years) of cardiovascular diseases, diabetes mellitus, and death identified in the follow-up surveys, Chin-Shan Community Cardiovascular study

\begin{tabular}{lccl}
\hline Events & $\begin{array}{l}\text { Male No. } \\
\text { (rate) }\end{array}$ & $\begin{array}{l}\text { Female No. } \\
\text { (rate) }\end{array}$ & $\begin{array}{l}\text { Male-to-Female RR } \\
(95 \% \text { CI })\end{array}$ \\
\hline $\begin{array}{l}\text { Disease } \\
\text { CAD }\end{array}$ & $51(8.7)$ & $48(7.2)$ & $1.21(0.82-1.79)$ \\
$\quad$ Hypertension & $290(49.2)$ & $289(43.4)$ & $1.13(0.96-1.33)$ \\
$\quad$ Stroke & $35(5.9)$ & $39(5.9)$ & $1.00(0.63-1.58)$ \\
$\quad$ Diabetes & $112(19.0)$ & $105(15.8)$ & $1.20(1.08-3.57)$ \\
Death & & & \\
CVD/sudden death & $67(7.0)$ & $42(5.3)$ & $1.32(0.90-1.94)$ \\
$\quad$ Cancer & $72(7.5)$ & $38(4.8)$ & $1.56(1.07-2.35)$ \\
$\quad$ Others & $90(9.4)$ & $60(7.5)$ & $1.25(0.90-1.73)$ \\
\hline
\end{tabular}

$\mathrm{RR}$ : relative risk, a rate ratio; $\mathrm{CI}$ : confidence interval. 
Table 7

The estimated relative risk of CAD, stroke, and DM incidence, and CVD/sudden death at follow-up evaluation by baseline sociodemographic factor, ChinShan Community Cardiovascular study

\begin{tabular}{|c|c|c|c|c|}
\hline & $\begin{array}{l}\text { CAD } \\
\text { OR (95\% C.I.) }\end{array}$ & $\begin{array}{l}\text { Stroke } \\
\text { OR (95\% C.I.) }\end{array}$ & $\begin{array}{l}\text { CVD/sudden death } \\
\text { OR (95\% C.I.) }\end{array}$ & $\begin{array}{l}\text { DM } \\
\text { OR (95\% C.I.) }\end{array}$ \\
\hline \multicolumn{5}{|l|}{ Gender } \\
\hline Male & $1.1(0.8-1.6)$ & $1.1(0.6-1.8)$ & $1.9(1.3-2.9)$ & $1.3(0.9-1.8)$ \\
\hline Female & 1.0 & 1.0 & 1.0 & 1.0 \\
\hline \multicolumn{5}{|l|}{ Age } \\
\hline $35-54$ & 1.0 & 1.0 & 1.0 & 1.0 \\
\hline $55-64$ & $2.4(1.5-3.7)$ & $2.4(1.2-4.9)$ & $2.5(1.2-5.0)$ & $1.6(1.2-2.3)$ \\
\hline $65+$ & $2.7(1.6-4.4)$ & $4.9(2.3-10.2)$ & $11.3(5.9-21.7)$ & $1.4(0.9-2.3)$ \\
\hline \multicolumn{5}{|l|}{ Married } \\
\hline No & 1.0 & 1.0 & 1.0 & 1.0 \\
\hline Yes & $0.9(0.4-2.4)$ & $0.5(0.2-1.3)$ & $2.6(0.8-8.5)$ & $0.9(0.4-2.0)$ \\
\hline \multicolumn{5}{|l|}{ Occupation } \\
\hline Blue collar & 1.0 & 1.0 & 1.0 & 1.0 \\
\hline White collar & $1.5(0.9-2.7)$ & $0.8(0.3-2.5)$ & $0.8(0.3-2.0)$ & $1.4(0.9-2.3)$ \\
\hline Others $^{\mathrm{a}}$ & $1.0(0.7-1.7)$ & $1.2(0.6-2.3)$ & $1.2(0.7-2.0)$ & $1.5(1.0-2.2)$ \\
\hline \multicolumn{5}{|c|}{ School Education } \\
\hline None & 1.0 & 1.0 & 1.0 & 1.0 \\
\hline Yes $^{\mathrm{b}}$ & $0.8(0.6-1.2)$ & $0.6(0.4-1.1)$ & $0.8(0.5-1.2)$ & $1.3(1.0-1.9)$ \\
\hline \multicolumn{5}{|l|}{ Insurance } \\
\hline Government & 1.0 & 1.0 & 1.0 & 1.0 \\
\hline Labor $^{\mathrm{c}}$ & $1.1(0.5-2.2)$ & $1.3(0.4-3.6)$ & $0.6(0.3-1.1)$ & $0.9(0.5-1.5)$ \\
\hline Other & $1.0(0.5-2.3)$ & $1.1(0.3-3.4)$ & $0.6(0.3-1.3)$ & $1.2(0.6-2.3)$ \\
\hline
\end{tabular}

CAD: coronary artery disease; DM: diabetes mellitus; OR: odds ratio; CI: confidence interval.

${ }^{\text {a }}$ Retired and unemployed.

${ }^{\mathrm{b}}$ Six years and above.

${ }^{\mathrm{c}}$ Labor insurance covered also farmers and fishermen.

more, smoking rates among men in Chin-Shan and Taiwan were more than double the rate of American men, although smoking rates were much lower among Taiwanese women than among American women $[43,44]$. Smoking cigarettes, particularly American cigarettes, has become fashionable for men in Taiwan and has increased from $40 \%$ in 1987 to the current rate of $60 \%$ [31,43]. Smoking has traditionally been considered inappropriate behavior for women in Taiwan, which accounts for the low smoking rate among women.

Some of the interesting findings revealed by the baseline information and lipid results were that although white-collar individuals had an elevated risk of having dyslipidemia (Table 5), with insignificantly elevated risk of diabetes and death from CAD (Table 7), they were not at an elevated risk of stroke or CVD/sudden death. This phenomenon suggests no strong evidence of a relationship between dyslipidemia and the likelihood of CVD events among social classes in this community cohort. Individuals with at least a primary school education are slightly less likely to hold blue-collar jobs and also have a slightly increased likelihood of having dyslipidemia because they are more affluent and presumably consume more calories from fat. White-collar individuals in general have received a school education and have better access to health care. These factors lead to a small and insignificant reduction from stroke and CVD/sudden death. On the other hand, they may have a higher risk of diabetes and death from $\mathrm{CAD}$, although this finding was also not statistically signifi- cant. Thus, the sociodemographic status in this cohort may have a significant association with the risk of dyslipidemia, but this effect is not strong enough to alter the overall risk of cardiovascular events. As the majority of the study population received no more than 9 years of education, the overall awareness of cardiovascular disease prevention may be low, yet at the same time this cohort is at risk for developing dyslipidemic because of improved economic status in recent years.

Although women in this study were generally younger than men, they were more likely than men to have hyperlipidemia. Similarly, hypertension was more prevalent in women, although they had lower prevalence rates of CVA and CAD than in men at baseline. Women also had a lower incidence of hypertension and CAD than men in the follow-up years. However, multivariate logistic regression analysis for the followup surveys revealed that men were 1.9 times more likely than women to have CVD/sudden death. We found that hypertension was the most important risk factor (risk ratio, $\mathrm{RR}=5.20$, $95 \% \mathrm{CI}=3.16,8.58$; data not shown), followed by smoking status $(\mathrm{RR}=2.34,95 \% \mathrm{CI}=1.23,4.46)$ and lower levels of HDL-C $(\mathrm{RR}=1.59,95 \% \mathrm{CI}=1.0,2.55)$. Because the smoking rate was as high as $62 \%$ in men, it is possible that patients with CVD have followed their physicians' suggestions to quit smoking but that they did not quit soon enough.

Based on the Chin-Shan baseline data, the population in Taiwan is at a higher risk than ever for CVD. Without modifications in dietary behavior and lifestyle, the incidence of CVD 
will remain at a peak level [21]. However, it is also important to identify the difference between men and women for incidence of dyslipidemia and CVD and deaths from cardiovascular events. The longitudinal nature of the CCCC project enhances its ability to identify risk factors for CVD. Further analyses will emphasize the secular changes in lipid profiles and other biomarkers from baseline to follow-up surveys, stratified by sociodemographic factors, and will investigate their associations with the development of new CVD cases and deaths. Intervention referrals have been provided to the study cohort and will be followed for individuals at higher risk.

\section{Acknowledgments}

This study was supported by research grants (DOH-7906, 80-30, 81-27, 82-TD-86, and DOH83-TD-95) from the Department of Health, Taiwan, Republic of China.

Appendix 1

Elements of baseline survey and examination in the Chin-Shan Community Cardiovascular study

\begin{tabular}{ll}
\hline Demographic variables & Sex, birth date, ethnicity, education, marital status, religion, insurance, occupation \\
Lifestyle factors & Smoking, alcohol, tea/coffee, betel nut, exercise, stress \\
Personal/family health history & Hypertension, diabetes, stroke, CAD, heart disease, arrhythmia, rheumatism, lipidemia, etc. \\
Blood pressure/anthropometry & Weight, height, skinfold, bellyfold, etc. \\
Physical examination & Heart, lung, extremities, spine, arcus senilis xanthelasma/xanthoma, other chest/heart/cardiovascular exams \\
Ultrasound/electrocardiogram & 2-Dimensional, M-mode measurement, Color and Doppler mapping, echocardiography \\
Eye fundography & Macular, eye ground, vessels characteristics \\
Blood/urine chemistry & Lipid profiles ${ }^{\mathrm{a}}$, uric acid, blood urea nitrogen, creatinine, pre-albumin, blood cell count, sugar, electrolytes.
\end{tabular}

aTotal cholesterol, triglycerides, high-density lipoprotein, low-density lipoprotein, lipoprotein(a), lipoprotein, apolipoprotein A1, apolipoprotein B, and coagulation factors.

Appendix 2

Laboratory measurements and methods used in the Chin-Shan Community Cardiovascular study

\begin{tabular}{lll}
\hline Specimen & Measurement & Method \\
\hline Blood & Total cholesterol & Enzymatic [45] \\
& Lipoprotein phenotyping & Precipitation [46, 47] \\
& Total triglycerides & Enzymatic [48] \\
& Blood count & Counter [49] \\
& Electrolytes & ISE (ion-selective-electrode) [50] \\
& Proteins & Biuret [51] \\
& Apolipoproteins & Turbitimetric immunoassay [52] \\
& Lipoprotein(a) & ELISA [53] \\
& Glucose & Enzymatic [54] \\
Urine & Electrolytes & ISE (ion-selective-electrode) [50]
\end{tabular}

\section{References}

[1] Dawber TR, Moore FE, Mann GV II. Coronary heart disease in the Framingham Study. Am J Prev Med 1957;47(suppl.):4-23.

[2] Gordon T, Moore FE, Shurtleff D, Dawber TR. Some methodological problems in the long-term study of cardiovascular disease: observation on the Framingham Study. J Chronic Dis 1959;10:186-206.

[3] Dawber TR. The Framingham Study. The Eidemiology of Atherosclerosis Disease. Cambridge, MA: Harvard University Press; 1980.

[4] Farquhar JW, Fortmann SP, Maccoby N, Haskell WL, Williams PE, Flora J, et al. The Stanford Five-City Project: design and methods. Am J Epidemiol 1985;122:323-34.

[5] Winkleby MA, Fortmann SP, Rockhill B. Trends in cardiovascular disease risk factors by educational level: the Stanford Five-City Project. Prev Med 1992;21:592-601.

[6] Welty TK, Lee LT, Yeh J, Cowan LD, Go O, Fabsitz RR, et al. Cardiovascular disease risk factors among American Indians- the Strong Heart Study. Am J Epidemiol 1995;142:269-87.

[7] Luepker RV, Murray DM, Jacobs DR Jr, Mittelmark MB, Bracht N. Community education for cardiovascular disease prevention: risk factor changes in the Minnesota Heart Health Program. Am J Public Health 1994;84:1383-93.

[8] The Aric Investigators. The atherosclerosis risk in communities
(ARIC) Study: design and objectives. Am J Epidemiol 1989;129: 687-702.

[9] Chambleess LE, McMahon RP, Brown SA, Patsch W, Heiss G, Shen YL. Short-term intraindividual variability in lipoprotein measurements: the atherosclerosis risk in communities (ARIC) Study. Am J Epidemiol 1992;136:1069-81.

[10] Freedman DS, Newman WP III, Tracy RE, Voors AW, Srinivasan $\mathrm{SR}$, Webber LS, et al. Black/white differences in aortic fatty streaks in adolescence and early adulthood: the Bogalusa Heart Study. Circulation 1988;77:856-64.

[11] Fried LP, Borhani NO, Enright P, Furberg CD, Gardin JM, Kronmal RA, et al. The cardiovascular health study: design and rationale. Ann Epidemiol 1991;1:263-76.

[12] Keys A. Coronary heart disease in seven countries. Circulation 1970; 41(suppl.):i1-i211.

[13] Colditz GA, Stampfter MJ, Willett WC. A prospective study of parental history of myocardial infarction and coronary heart disease in women. Am J Epidemiol 1986;123:48-58.

[14] Rimm EB, Giovannucci EL, Stampfer MJ, Colditz GA, Ascherio A, Rosner B, et al. A prospective study of alcohol consumption and the risk of coronary disease in men. Lancet 1991;338:464-8.

[15] MacLean DR, Petrasovits A, Nargundkar M, Connelly PW, Mac Leod E, Edwards A, et al. Canadian heart health surveys: a profile of cardiovascular risk, survey methods and data analysis. CMAJ 1992; 146:1969-74.

[16] Goldman L, Cook EF. The decline in ischemic heart disease mortality rates-an analysis of the comparative effects of medical interventions and changes in lifestyle. Ann Intern Med 1984;101:825-36.

[17] Beaglehole R. Cardiovascular disease in developing countries. BMJ 1992;305:1170-711.

[18] World Heath Organization. World Health Statistics Annual 1991. Geneva: WHO, 1992. pp. 25-6.

[19] Najeeb M. Cardiovascular disease in developing countries. BMJ 1993;306:927.

[20] Hughes K. Trends in mortality from ischaemic heart disease in Singapore, 1959 to 1983. Int J Epidemiol 1986;15:44-50.

[21] Health and Vital Statistics I and II. Taipei, Taiwan: Department of Heath, 1990

[22] Gillum RF, Feinleib M. Cardiovascular disease in the United States: Mortality, prevalence and incidence. In: Kapoor AS, Singh BN, Eds. 
Prognosis and Risk Assessment in Cardiovascular Disease. New York: Churchill Livingstone; 1993:49-59.

[23] Economic Yearbook of the Republic of China. Taipei, Taiwan: Economic Daily News, 1995. pp. 134-47.

[24] National Diabetes Data Group. Classification and diagnosis of diabetes mellitus and other categories of glucose intolerance. Diabetes 1979;28:1039-57.

[25] Su TC, Chen PR, Chien KL, Hu SP, Hsu HC, Sung FC, Lee YT. The effect of dietary therapy on patients with hypercholesterolemia in Chin-Shan Community - a three-month intervention. J Intern Med Taiwan 1997;8:18-29.

[26] Criteria Committee of the New York. Heart Association Nomenclature and Criteria for Diagnosis of Diseases of the Heart and Blood Vessels, 8th ed. Boston: Little, Brown and Company, 1979.

[27] Izzo JL Jr, Black HR, editors. Hypertension primer, from Council on High Blood Pressure Research. Dallas, TX: American Heart Association, 1993.

[28] American Heart Association. Recommendations for Human Blood Pressure Determination by Sphygmomanometers. 1987.

[29] Prineas RRJ, Grow RS, Blackburn H. The Minnesota Code Manual of Electrocardiographic Findings: Standards Procedures for Measurement and Classification. Boston, Bristol: John Wright, 1982.

[30] National Cholesterol Education Progrom, Second Report of the Expert Panel. Detection, evaluation, and treatment or high blood cholesterol in adults (Adult Treatment Panel II). Circulation 1994;89:1330-448.

[31] Reed D, Maclean C. The nineteen-year trends in CHD in the Honolulu Heart Program. Int J Epidemiol 1989;18:S82-7.

[32] McDonough JR, Hames CG, Stulb SC, Garrison GE. Coronary heart disease among negroes and whites in Evans County, Georgia. J Chronic Dis 1995;18:443-68.

[33] WHO. WHO MONICA Project: objectives and design. Int J Epidemiol 1989;18:S29-37.

[34] Tseng WP. Epidemiological study on cardiovascular disease in rural area. 1974 Unpublished.

[35] Tseng YZ. Epidemiological study on cardiovascular disease in rural area. 1991. Unpublished.

[36] Directorate-General of Budget, Accountant and Statistics, Executive Yuan. Republic of China Annual Statistics. Taipei, Taiwan, 1996, p. 122.

[37] Yen LL, Pan LY, Yen HW, Lee LA. The smoking status in adults in Taiwan area: Prevalence rates and risk factors. Chinese Med J (Taipei) 1994;13:371-80.

[38] Chiang TL, Lin RS. Patterns of cigarette smoking in Taiwan-findings from 1990 National Health Interview Survey. Abstract 120th Annual Meeting of American Public Health Association. Washington DC, 1992.
[39] Chou P, Chen CH, Chiu CF, Chang MS. Community-based epidemiology study on hypertension in Pu-Li, Taiwan. Am J Hypertens 1992; 5:608-15.

[40] Chen CH, Chuang JH, Kuo HS, Chang MS, Wang SP, Chou P. Epidemiology of cardiovascular risk factors in Kin-Chen, Kinmen. Int $\mathrm{J}$ Cardiol 1995;48:75-88.

[41] P.R.C.-U.S.A. Cardiovascular and Cardiopulmonary Epidemiology Research Group. An epidemiological study of cardiovascular and cardiopulmonary disease risk factors in four populations in the People's Republic of China-baseline report from the P.R.C.-U.S.A. Collaborative Study. Circulation 1992;85:1083-96.

[42] Burt VL, Whelton P, Roccella EJ, Brown C, Cutler JA, Higgins M, Horan MJ, Labarthe D. Prevalence of hypertension in the US adult population-Results from the Third National Heath and Nutrition Examination Survey, 1988-1991. Hypertension 1995;25:305-13.

[43] Taiwan Tobacco and Wine Statistical Yearbook. Taipei: Taiwan Tobacco and Wine Monopoly Bureau. 1993. p. 8.

[44] Cigarette smoking among adults-United States, 1991. MMWR 1993;42:230-3.

[45] Allain LA, Poon LS, Chan LSG, Richmond W, Fu PL. Enzymatic determination of total cholesterol. Clin Chem 1974;20:470-5.

[46] Wieland H, Seeidel D. A simple specific method for precipitation of low density lipoproteins. J Lipid Res 1983;24:904-9.

[47] Warnick GR, Benderson, Albers JJ. Dextran sulfate- $\mathrm{Mg}^{2+}$ precipitation procedure for quantitation of high density-lipoprotein cholesterol. Clin Chem 1982;28:1379-88.

[48] McGown MW, Artiss JD, Strandberg DR, Zak B. A peroxidase-coupled method for the colorimetric determination of serum triglycerides. Clin Chem 1983;29:538-42.

[49] Henry JB, editor. Clinical Diagnosis and Management by Laboratory Methods, 17th ed. Philadelphia: W.B. Saunders Co., 1984.

[50] Lustgarten JA, Wenk RE, Byrd C, Hall B. Evaluation of an automated selective-ion electrolyte analyzer for measuring $\mathrm{Na}^{+}, \mathrm{K}^{+}$, and $\mathrm{Cl}^{-}$in serum. Clin Chem 1974;20:1217-21.

[51] Kingsley GR. The direct biuret method for the determination of serum proteins as applied to photoelectric and visual colorimetry. J Lab Clin 1942;27:840-5.

[52] Rifai N, King ME. Immunoturbidimetric assays of apolipoproteins A-1, A-2 and B in serum. Clin Chem 1986;32:957-60.

[53] Fless GM, Snyer ML, Scanu AM. Enzyme-linked immunoassay for Lp(a). J Lipid Res 1989;30:651-62.

[54] Banauch D, Brummer W, Ebeling W, Metz H, Rindfrey H, Lang H, et al. A glucose dehydrogenase for the determination of glucose concentrations in body fluids. Zeit Klin Chem Klin Biochem 1975;13:101-7. 